\title{
Effect of neonatal hyperthyroidism on GH gene expression reprogramming and physiological repercussions in rat adulthood
}

\author{
Kely de Picoli Souza, Francemilson Goulart da Silva and Maria Tereza Nunes \\ Department of Physiology and Biophysics, Institute of Biomedical Sciences, University of São Paulo, 05508-900 São Paulo, SP, Brazil \\ (Requests for offprints should be addressed to M T Nunes; Email: mtnunes@icb.usp.br)
}

\begin{abstract}
The neonatal period (NP) is a critical phase of the development in which the expression pattern of most genes is established. Thyroid hormones (TH) play a key role in this process and, alterations in its availability in the NP may lead to different patterns of gene expression, which might reflect in the permanent expression of several genes in the adulthood. GH gene expression in the pituitary is greatly dependent on $\mathrm{TH}$ in the early postnatal life; thus, modifications of thyroid state in NP might lead to alterations in GH gene expression as well as to physiological repercussions in the adult life. This study aimed to investigate this possibility by means of the induction of a neonatal hyperthyroidism in rats $(4 \mu \mathrm{g}$ of 3,5,3'-triiodo-L-thyronine (T3)/100 g body weight, s.c.) for 5,15 or 30 days, and further evaluation of $\mathrm{GH}$ gene expression, as well as its physiological consequences in adult

rats subjected to a transient hyperthyroidism in the first 30 days of life. GH mRNA level was shown to be increased in T3-treated rats for 5 days; when the treatment was extended to 15 or 30 days, the GH mRNA levels were similar to the control group. Moreover, rats treated with T3 for 30 days and killed when 90 days old, i.e., 60 days at the end of the T3 treatment, showed decreased GH mRNA content, body weight, bone mineral density, and lean body mass. In conclusion: (1) T3 effects on GH gene expression depend on the period of life in which the hyperthyroidism is set and on the length of T3 treatment in the NP and (2) transient neonatal hyperthyroidism leads to a lower GH mRNA expression in adult life accompanied by physiological repercussions indicative of $\mathrm{GH}$ deficiency.

Journal of Endocrinology (2006) 190, 407-414
\end{abstract}

\section{Introduction}

In mammals, many tissues are not completely developed at birth (Kominami et al. 2003, Nakahara et al. 2005), which means that the pattern of expression of many genes is not defined entirely. Therefore, the neonatal period (NP) is an important stage of life in which hormonal, neuronal, and metabolic disturbances may influence the program of expression of some genes in the adult life.

Dussault \& Labrie (1975) have demonstrated in rats that thyroid hormone serum concentrations are low at birth and increase progressively achieving the adult values approximately at the third week of life, when the maturation of the hypothalamus-pituitary-thyroid (HPT) axis is accomplished. While the set point of the thyroid-releasing hormone (TRH) and thyroid-stimulating hormone (TSH) secretion control is being established (Pracyk et al. 1992), the expression of different thyroid hormone receptor (TR) isoforms and the activity of different types of deiodinases in several tissues try to assure a stable supply of thyroid hormones (TH) to tissues, avoiding deleterious effects caused by temporary low or high levels of these hormones (Bates et al. 1999, White et al. 2001). These adjustments denote the physiological importance of

$\mathrm{TH}$ for the body economy at this period, in which the patterns of expression of most genes are being established.

In effect, studies have demonstrated that the induction of a transient hyperthyroidism in rats at NP lead, at the adult life, to a deficit on the mielinization of the nerve cells (for review, see Pasquini \& Adamo 1994), a decrease in the number of oligodendrocytes by activation of apoptotic mechanisms (Marta et al. 1998), alterations in the number and function of the Leydig cells (Teerds et al. 1998), a decrease in T4 response to exogenous TSH (Csaba \& Nagy 1985), and a decrease in the $\beta$-adrenergic receptor's density at myocardium (Novotny et al. 1999), among other effects.

Even though these studies show a clear correlation between precocious events induced transiently at the postnatal life and associated repercussions at the adult life, the molecular basis underlying these events is not fully known. In this context, the first month of life is an attractive period to study the transition from the fetal/neonatal to the adult pattern of expression of several genes that are under the control of $\mathrm{TH}$.

Most of the TH effects result from their interaction with TRs (Webb 2004) previously bound to the thyroid hormone response element (Harvey \& Williams 2002), located in several target genes. One of them is the growth hormone (GH) gene, 
whose expression is induced by 3,5,3'-triiodo-L-thyronine (T3) and reduced in hypothyroid states (Samuels \& Shapiro 1976, Volpato \& Nunes 1994).

$\mathrm{GH}$ is known to exert important physiological actions on the skeletal longitudinal growth as well as on glucose, amino acid, and fatty-acid metabolism (Mauras et al. 2000, Robson et al. 2002). Impaired GH expression has been associated with disturbed body growth and fuel metabolism (Okada \& Kopchick 2001).

The aim of the present study is to investigate the GH gene responsiveness to T3 treatment during the first month of life in rats and whether the transient postnatal hyperthyroidism alters the GH gene expression permanently in the adult life. We further evaluated, in the adult animals, the possible repercussions of a transient postnatal hyperthyroidism in the body weight $(\mathrm{BW})$ and size, body composition, and bone mineral density (BMD), parameters that are under $\mathrm{GH}$ control.

\section{Materials and Methods}

\section{Animals and treatments}

All aspects of animal care and experimentation performed in this study agree with ethical principles in animal research adopted by the Brazilian College of Animal Experimentation (COBEA) and was approved by the Institute of Biomedical Sciences of the University of São Paulo-Ethical Committee for Animal Research (CEEA).

Pregnant Wistar rats were obtained from the breeding colony of the Institute of Biomedical Sciences. They had free access to commercial chow and tap water, in a temperaturecontrolled room $\left(23 \pm 1^{\circ} \mathrm{C}\right)$ with a $12 \mathrm{~h}$ light: $12 \mathrm{~h}$ darkness cycle (lights on at $0700 \mathrm{~h}$ ). Male Wistar newborn rats, weighing approximately $6 \mathrm{~g}$, were used in this study. Each litter consisted of approximately eight rats per dam and was randomly assigned to one of the two treatment groups: (1) control- or (2) T3-treated group (Hyper).

Treatment of each group was started on the first day (P1) after birth (P0) and was conducted as follows: control rats received s.c. injections of $0.9 \% \mathrm{NaCl}$ and $\mathrm{T} 3$-treated rats received s.c. injections of T3 (Sigma, $4 \mu \mathrm{g} / 100 \mathrm{~g} \mathrm{BW}$ ), every day during 5,15 or 30 days starting one day after birth (P1) and these animals were named as Hyper5, Hyper15, and Hyper30 respectively. After this period, the animals were weighed and killed by decapitation. The pituitary was removed quickly for RNA extraction. To check the efficiency of the T3 treatment, heart ventricle weights and the day pups opened their eyes were determined. Blood samples were collected to evaluate the concentrations of T3 and T4 by RIA (Diagnostic Products Corporation, Llamberis, UK) in sera, using a standard curve prepared with different concentrations of T3 or T4 in iodothyronine-free rat serum.

In order to evaluate the $\mathrm{T} 3$ serum clearance rate, an additional study was carried out in rats subjected to $\mathrm{T} 3$ or saline for 15 days from birth. It consisted of a time-course study of T3 serum concentration in which the rats were killed $30 \mathrm{~min}, 2,6$, and $15 \mathrm{~h}$ after the last $\mathrm{T} 3$ injection.

For the GH gene-reprogramming studies, the animals were treated with T3 $(4 \mu \mathrm{g} / 100 \mathrm{~g} \mathrm{BW}$, s.c.) for 30 days. The treatment was suspended by 60 days and these animals, named as postnatal transient hyperthyroid rats, had their size $(\mathrm{cm})$, $\mathrm{BW}(\mathrm{g})$, body composition (fat and lean mass, $\mathrm{g} / \mathrm{cm}^{2}$ ), and BMD $\left(\mathrm{g} / \mathrm{cm}^{2}\right)$ determined. They were killed afterwards and had their GH mRNA expression, T4 and T3 serum levels evaluated. Each experiment included four rats per group and was repeated three times.

The T3 dose used to induce hyperthyroidism $(4 \mu \mathrm{g} / 100 \mathrm{~g}$ $\mathrm{BW})$ was 13 times higher than the physiological replacement dose of T3, which is postulated to be $0 \cdot 3 \mu \mathrm{g} / 100 \mathrm{~g} \mathrm{BW}$ (Dillmann et al. 1983), and lower than those used in similar studies (Yamazoe et al. 1989, Cernohorsky et al. 1998).

\section{Total RNA extraction and Northern blot analysis}

Total RNA was isolated using the acid guanidinium thiocyanate-phenol-chloroform extraction method (Chomczynski \& Sacchi 1987) and quantified by absorbance at $260 \mathrm{~nm}$. Six micrograms of total RNA samples were denatured with formaldehyde-formamide, electrophoresed in $1 \%$ agarose gels containing $2 \cdot 2 \mathrm{M}$ formaldehyde in $1 \times 3-n$-morpholinopropanesulfonic acid (MOPS) buffer and blotted to a nylon membrane (Nylon-1 membrane; Gibco) by neutral capillary transfer. The membrane was baked at $80^{\circ} \mathrm{C}$ for $2 \mathrm{~h}$ in a vacuum oven and pre-hybridized in 50\% formamide hybridization solution and $100 \mu \mathrm{g} / \mathrm{ml}$ denatured salmon sperm DNA at $42{ }^{\circ} \mathrm{C}$ for $4 \mathrm{~h}$ (Maniatis et al. 1989). Subsequently, the membrane was probed with a ${ }^{32} \mathrm{P}$-labeled rat GH cDNA by random priming (Random Primers DNA Labeling System kit; Gibco) for $16 \mathrm{~h}$ at $42{ }^{\circ} \mathrm{C}$. The membrane was washed under highly stringent conditions and subjected to autoradiography and quantified by phosphor imaging, using the ImageQuant software (Molecular Dynamics, Sunnyvale, CA, USA). All blots were stripped and re-hybridized with a ${ }^{32} \mathrm{P}$-labeled RNA probe specific for $18 \mathrm{~S}$ ribosomal subunit (18S rRNA), synthesized by in vitro transcription (Maxi Script in vitro transcription kit; Ambion, Austin, TX, USA), to correct for the variability in RNA loading. The results were expressed as mean \pm s.E.M. of GH mRNA/18S rRNA ratio.

\section{Body composition and BMD determination}

Body composition, lean and fat mass, and BMD were measured by dual energy X-ray absorptiometry using the pDEXA Sabre Bone Densitometer and the pDEXA Sabre Software version 3.9.4 (Norland Medical Systems, Fort Atkinson, WI, USA), both designed especially for small animals (Stikkelbroeck et al. 2003). The research mode scan option was used for the measurements. Pixel spacing for the scan was set to $0.5 \times 0.5 \mathrm{~mm}$ and the scan speed to $4 \mathrm{~mm} / \mathrm{s}$. To limit the scan area, which allows the scans to be performed in a higher resolution mode, the scans were performed from 
the first lumbar vertebra to the hind limbs. The analyzed region was the hind body, which includes L2-L6, pelvic bones, hind limbs, and the first four caudal vertebrae. For the scans, the animals were anesthetized with a ketamine-xylazine cocktail and scanned in the prone position. The animals were scanned at 90 days of life (after 60 days, the treatment was completed).

\section{Statistical analysis}

The data were subjected to one-way ANOVA, followed by the Student-Newman-Keuls test and Student's $t$-test, when only two groups were compared. They were expressed as means \pm s.E.M. Differences were considered significant at $P<0 \cdot 05$.

The data of the time-course study of total T3 serum concentrations of euthyroid and hyperthyroid rats treated with $\mathrm{T} 3$ from $\mathrm{P} 1$ to $\mathrm{P} 15$, after $30 \mathrm{~min}, 2,6$, and $15 \mathrm{~h}$ of a single injection of $\mathrm{T} 3$ were entered into two-way ANOVA with time (h) and treatment as the two independent variables, followed by the Student-Newman-Keuls test for multiple comparisons.

\section{Results}

The effectiveness of T3 treatment was checked by determining the ratio between heart ventricular weight and body weight (VW/BW), the day of the eye opening (DEO) and T4 serum concentration. Rats treated with T3 (4 $\mu \mathrm{g} / 100 \mathrm{~g} \mathrm{BW}$, s.c.) for 5,15 , and 30 day-periods from birth presented an increase in the VW/BW ratio, whereas the DEO and T4 levels were decreased, as expected. These data are presented in Table 1 and confirm the induction of hyperthyroidism. In addition, T3 serum concentrations were increased in rats treated with the hormone for 5- and 30-day period being similar to control values after 15 days of the treatment (Table 1$)$.

The following is shown in Figs 1 and 2: (A) the typical Northern blot of one experiment from a total of three experiments and $(\mathrm{B})$ the quantitative representation of the hybridization of rat $\mathrm{GH}$ and $18 \mathrm{~S}$ rRNA transcripts obtained by densitometric analysis, expressed as mean \pm s.E.M. of $\mathrm{GH}$ mRNA/18S rRNA ratios from all the experiments performed. An increase in GH mRNA levels in rats treated with T3 for a 5-day period was observed; however, when T3 treatment was extended to 15 and 30 days, no significant difference in GH mRNA content was detected compared to the control group (Fig. 1). The GH mRNA expression was also estimated in 90-day-old adult rats, which were subjected to a transient hyperthyroidism ( $4 \mu \mathrm{g}$ of $\mathrm{T} 3 / 100 \mathrm{~g} \mathrm{BW}$, s.c.) from P1 to P30 and allowed to grow with no further T3 treatment until P90 (Fig. 2). These rats presented a decrease in GH mRNA content, when compared to the control group. The same occurred with their nose-tail length and BMD, whereas the VW/BW ratio and $\mathrm{T} 4$ serum levels remained similar to the control group (Table 2).

Figure 3 illustrates the body composition (lean and fat mass) of rats treated with T3 from P0 to the 30th day of life, when they were killed, as well as at their 90th day of life, following 60 days after the treatment was ended, i.e., after the rats were subjected to transient hyperthyroidism during their first month of life. As observed, 30 days of T3 treatment resulted in a dramatic reduction of fat mass with no corresponding alteration in the lean mass. However, 60 days after the induction of the transient hyperthyroidism by T3 treatment from $\mathrm{P} 1$ to $\mathrm{P} 30$, the animals presented lower lean mass compared to their respective control, with no significant variation in the fat mass.

Figure 4 shows a time-course study of total T3 serum concentrations (ng/dl) of euthyroid and hyperthyroid animals (treated with $4 \mu \mathrm{g}$ of T3/100 $\mathrm{g}$ of BW from P1 to P15), after $30 \mathrm{~min}, 2,6$, and $15 \mathrm{~h}$ of a single injection of T3 $(4 \mu \mathrm{g} / 100 \mathrm{~g}$ of $\mathrm{BW})$. In the hyperthyroid rats, the $\mathrm{T} 3$ injection induced an increase of $\sim 9$ times in T3 serum levels, from $30 \mathrm{~min}$ to $2 \mathrm{~h}$, followed by a decrease to half of this value at $6 \mathrm{~h}$ of injection and return to the $\mathrm{T} 3$ values detected before $\mathrm{T} 3$ administration (0 min). The control animals presented a completely different time-course pattern of T3 serum levels, since an increase of

Table 1 Body weight (BW), ventricular weight (VW), ventricular weight to body weight ratio (VW/BW), day of eye opening (DEO) and serum $\mathrm{T} 3$ and T4 concentrations of T3-treated rats $(4 \mu \mathrm{g} / 100 \mathrm{~g}$, s.c.) for 5, 15, and 30 days. Rats treated with vehicle $(\mathrm{NaCl} 0.9 \%)$ were used as control

Days of treatment
after birth
Groups
BW $(\mathrm{g})$
VW $(\mathrm{mg})$
VW/BW $(\mathrm{mg} / \mathrm{g})$
DEO (postnatal days)
T3 (ng/ml)
T4 $(\mathrm{ng} / \mathrm{ml})$

5

\begin{tabular}{|c|c|}
\hline Control & Hyper \\
\hline $14 \cdot 8 \pm 0 \cdot 7$ & $13 \cdot 6 \pm 0 \cdot 5$ \\
\hline $90 \cdot 0 \pm 4 \cdot 0$ & $161 \cdot 0 \pm 8 \cdot 0^{*}$ \\
\hline $6 \cdot 1 \pm 0 \cdot 3$ & $11 \cdot 8 \pm 0 \cdot 3 \neq$ \\
\hline $0 \cdot 24 \pm 0 \cdot 02$ & $0 \cdot 56 \pm 0 \cdot 04 \neq$ \\
\hline $28 \cdot 05 \pm 0 \cdot 83$ & $13 \cdot 77 \pm 0 \cdot 46 \neq$ \\
\hline
\end{tabular}

15

\begin{tabular}{cc}
\hline Control & Hyper \\
\cline { 1 - 1 } $24 \cdot 2 \pm 1 \cdot 9$ & $22 \cdot 7 \pm 1 \cdot 9$ \\
$107 \cdot 0 \pm 10 \cdot 0$ & $152 \cdot 0 \pm 23 \cdot 0 \dagger$ \\
$4 \cdot 4 \pm 0 \cdot 3$ & $6 \cdot 8 \pm 0 \cdot 2 \ddagger$ \\
13 & 11 \\
$0 \cdot 38 \pm 0 \cdot 05$ & $0 \cdot 24 \pm 0 \cdot 05$ \\
$66 \cdot 05 \pm 3 \cdot 27$ & $15 \cdot 23 \pm 0 \cdot 91 \neq$
\end{tabular}

30

\begin{tabular}{|c|c|}
\hline Control & Hyper \\
\hline $87 \cdot 0 \pm 2 \cdot 9$ & $71 \cdot 6 \pm 3 \cdot 5 t$ \\
\hline $310 \cdot 0 \pm 20 \cdot 0$ & $480 \cdot 0 \pm 20 \cdot 0^{*}$ \\
\hline $3 \cdot 6 \pm 0 \cdot 1$ & $6 \cdot 7 \pm 0 \cdot 3 \neq$ \\
\hline $\begin{array}{c}13 \\
0 \cdot 35 \pm 0 \cdot 03\end{array}$ & $\begin{array}{c}11 \\
0 \cdot 51 \pm 0 \cdot 04 t\end{array}$ \\
\hline $39 \cdot 52 \pm 0 \cdot 52$ & $14 \cdot 20 \pm 1 \cdot 71$ \\
\hline
\end{tabular}

Results are expressed by means \pm s.E.M. $* P<0 \cdot 05,+P 0 \cdot 01, \neq P<0 \cdot 001$ compared with the control group ( $n=12$ per group). 

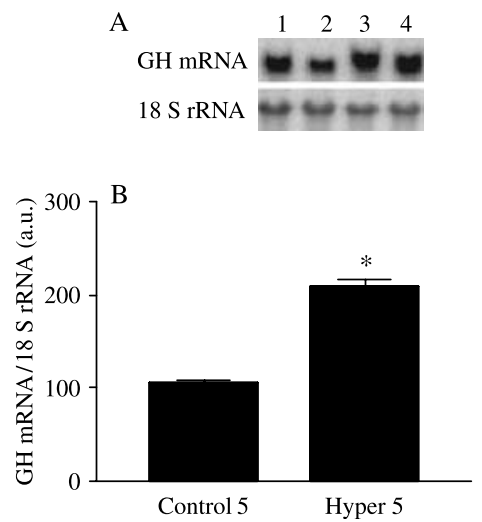

$\begin{array}{llll}1 & 2 & 3 & 4\end{array}$

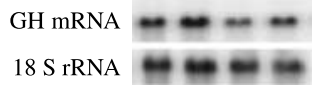

$\begin{array}{llll}1 & 2 & 3 & 4\end{array}$

18 S rRNA

GH mRNA
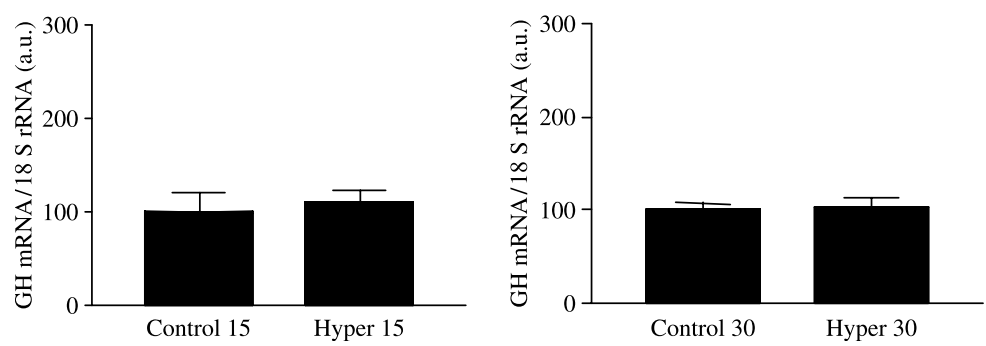

Figure 1 Northern blot analysis of GH mRNA of rats treated with vehicle (1 and 2) or $4 \mu \mathrm{g}$ of 3,5,3'-triiodo-L-thyronine (T3)/100 g body weight (BW) (3 and 4), s.c. for 5, 15, or 30 days from birth. (A) Northern blot analysis of GH mRNA levels of one experiment from a total of three experiments of (1 and 2) control and ( 3 and 4) T3-treated rats. (B) Quantitative representation of hybridization of $\mathrm{rGH}$ and $18 \mathrm{~S}$ rRNA transcripts obtained by densitometric analysis of the exposed films, in arbitrary units (a.u.). Results are expressed as means \pm S.E.M. of GH mRNA/18S rRNA ratios. ${ }^{*} P<0 \cdot 001$ compared with the control group.

$\sim 4$ times of $\mathrm{T} 3$ serum concentration was detected from 30 min throughout $15 \mathrm{~h}$ of the T3 administration.

\section{Discussion}

GH exerts a significant role on body growth and metabolism in postnatal life. The transcriptional induction of $\mathrm{GH}$ gene expression by $\mathrm{TH}$ is well documented in this period (Williams et al. 1991), but few studies have sought to understand the regulation of $\mathrm{GH}$ expression by $\mathrm{TH}$ in the $\mathrm{NP}$, as well as the physiological repercussions, in the adult life, of a transient hyperthyroidism induction at early postnatal life.

We reported herein that $\mathrm{T} 3$ effects on $\mathrm{GH}$ mRNA expression depend on the period of life in which the hyperthyroidism is established and, in the NP, on the length of T3 treatment. We also showed that transient neonatal hyperthyroidism leads to a lower GH mRNA expression in adult life accompanied by physiological repercussions indicative of $\mathrm{GH}$ deficiency.

T3 treatment for a 5-day period from birth increased the $\mathrm{GH}$ mRNA levels, as occurs in adult rats subjected to the same treatment schedule (Volpato \& Nunes 1994). On the other hand, when the T3 treatment was extended to 15 and 30 days, the GH mRNA content did not differ from the values of the control group, a result that diverges from the increased $\mathrm{GH}$ mRNA expression observed in adult animals that underwent the same treatment program. T3 serum concentration followed a similar trend of changes observed in $\mathrm{GH}$ expression except for rats treated with $\mathrm{T} 3$ for a 30-day period in which an increase was observed. The specific responses to T3 treatment for a 15-day period is thought to result from homeostatic adjustments elicited in order to reduce the impact of a high T3 supply to tissues, since the pattern of expression of many genes is not entirely defined yet, and could be influenced by $\mathrm{TH}$, as pointed out earlier.
Therefore, it is not surprising to observe that T3 serum concentrations of T3-treated rats for 15 days were similar to those obtained in the control group, considering that the activity of type-3 deiodinase (D3), an enzyme that converts T3 to T2, is relatively high in neonates (Bates et al. 1999) and that D3 is upregulated by T3 (St Germain \& Galton 1997, Tu et al. 1999). In fact, the time-course profile of the T3 serum

A
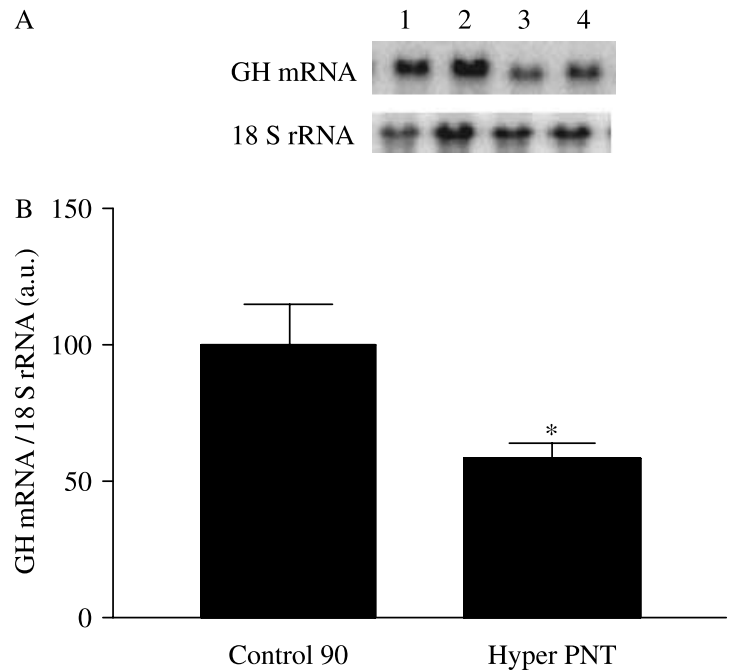

Figure 2 Northern blot analysis of $\mathrm{GH}$ mRNA of rats treated with vehicle ( 1 and 2 ) or $4 \mu \mathrm{g}$ of T3/100 g BW ( 3 and 4), s.c., for 30 days from birth, and allowed to grow with no further T3 treatment until 90 days of life (HyperPNT). (A) Northern blot analysis of GH mRNA levels of one experiment from a total of three experiments, of (1 and 2) control 90 and (3 and 4) HyperPNT. (B) Quantitative representation of hybridization of $\mathrm{rGH}$ and $18 \mathrm{~S}$ rRNA transcripts obtained by densitometric analysis of the exposed films, in arbitrary units (a.u.). Results are expressed as means \pm s.E.M. of $\mathrm{GH}$ mRNA/18S rRNA ratios. ${ }^{*} P<0 \cdot 001$ compared with the control group. 
Table 2 Nose-anal length (L), BW, VW, VW/BW ratio, serum T4 and $\mathrm{T} 3$, and bone mineral density (BMD) of rats treated with vehicle (control) or T3, $(4 \mu \mathrm{g} / 100 \mathrm{~g}$, s.c.) for the first 30 days of life, and killed at 90th day of life (HyperPNT)

Days of postnatal life

Groups
$\mathrm{L}(\mathrm{cm})$
BW $(\mathrm{g})$
VW $(\mathrm{mg})$
VW/BW $(\mathrm{mg} / \mathrm{g})$
T4 $(\mathrm{ng} / \mathrm{ml})$
T3 $(\mathrm{ng} / \mathrm{ml})$
BMD $\left(\mathrm{g} / \mathrm{cm}^{2}\right)$

90

\begin{tabular}{cc} 
Control & HyperPNT \\
\cline { 1 - 1 } $25 \cdot 55 \pm 0 \cdot 34$ & $214 \cdot 14 \pm 0 \cdot 46$ \\
$266 \cdot 93 \pm 7 \cdot 79$ & $550 \pm 2 \cdot 18^{*}$ \\
$720 \pm 20$ & $2 \cdot 60 \pm 0 \cdot 09$ \\
$2 \cdot 70 \pm 0 \cdot 10$ & $67 \cdot 71 \pm 5 \cdot 80$ \\
$55 \cdot 02 \pm 3 \cdot 29$ & $0 \cdot 23 \pm 0 \cdot 05$ \\
$0 \cdot 31 \pm 0 \cdot 03$ & $0 \cdot 113 \pm 0 \cdot 001^{*}$ \\
$0 \cdot 131 \pm 0 \cdot 003$ &
\end{tabular}

Results are expressed by means \pm s.E.M. ${ }^{*} P<0 \cdot 001$ compared with the control group ( $n=12$ per group).

concentration exhibited by these animals after the administration of a single dose of $\mathrm{T} 3$ confirmed the rapid $\mathrm{T} 3$ clearance rate. These findings also explain why T3-treated animals presented T3 serum concentration similar to control
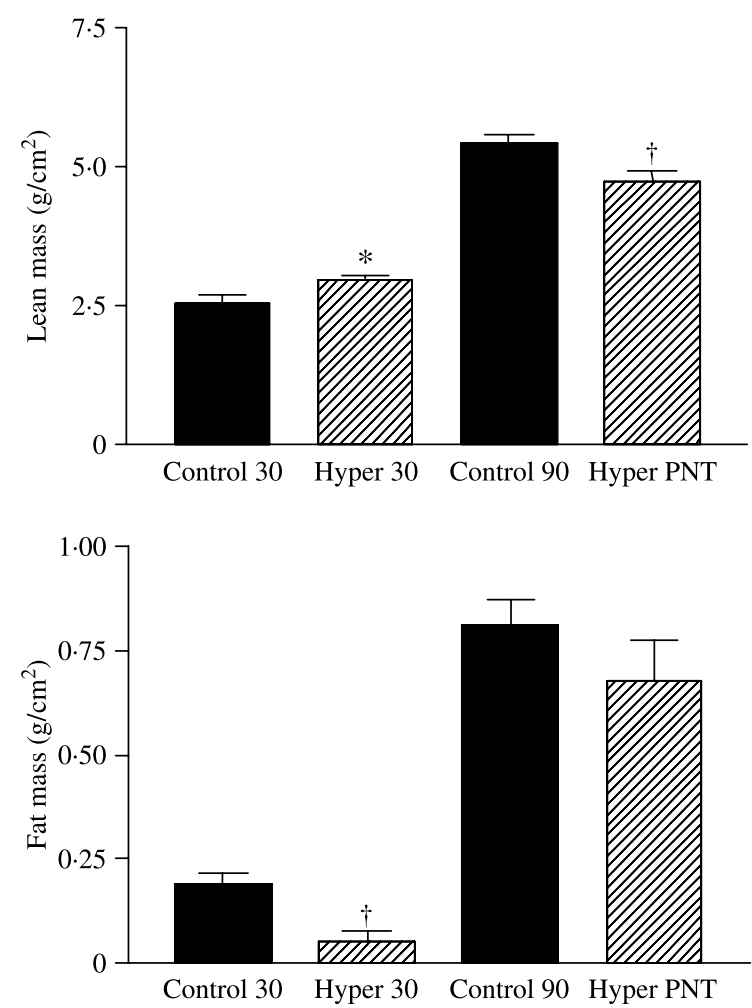

Figure 3 Body composition of rats treated with vehicle or $4 \mu \mathrm{g}$ of T3/100 g BW, s.C., for 30 days (Control 30 and Hyper 30 respectively), and of rats subjected to the same treatment schedule (30 days), but allowed to grow with no further T3 treatment until 90 days of life (control 90 and HyperPNT). The upper and lower panels present the data of lean and fat body mass respectively. Results are expressed as means \pm S.E.M. ${ }^{*} P<0 \cdot 05,+P 0 \cdot 01$ compared with the control group.

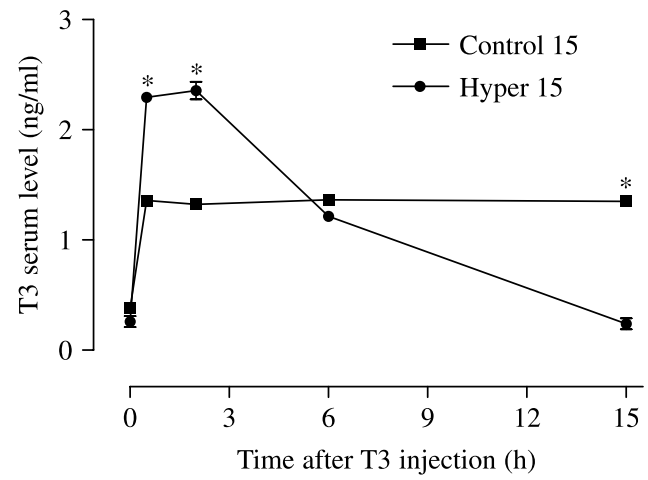

Figure 4 Time-course study of total T3 serum concentrations (ng/dl) of euthyroid (squares) and hyperthyroid animals treated with $4 \mu \mathrm{g}$ of T3/100 g BW from P1 to P15 (circles), after 30 min, 2, 6, and $15 \mathrm{~h}$ of a single injection of T3 (4 $\mu \mathrm{g} / 100 \mathrm{~g} \mathrm{BW})$. Results are expressed as means \pm S.E.M. ${ }^{*} P<0 \cdot 001$ compared with the control group.

values at the time of the sacrifice, which occurred $15 \mathrm{~h}$ after the administration of the hormone, despite the clear signs of hyperthyroidism (Fig. 4). Indeed, the increased VW/BW ratio, anticipation of the DEO (11th day of life), and decreased T4 serum concentration (Table 1 and Fig. 3) are important physiological indications of the hyperthyroid state, considering the well-known effects of TH inducing cardiac hypertrophy, maturation of the nervous system (Fisher \& Lakshmanan 1990, Heron \& Rakusan 1996, Yilmazer-Hanke et al. 2004), and feedback inhibition of HPT axis (Wolf 2002). In fact, one of the most precocious phenotypic signs of the maturation of nervous system is the time at which the pups' eyes open, which is achieved by the 13 th day of life.

The unaltered GH mRNA expression in hyperthyroidism during this specific period of life (15 and 30 days of T3 treatment from P1) was also an intriguing finding. However, it is well documented that, in hyperthyroid states, type-2 deiodinase (D2) activity is decreased in pituitary, central nervous system, and brown adipose tissue (Bates et al. 1999, Schneider et al. 2001, Volpato \& Nunes 2001). Moreover, in the early postnatal life, changes in the expression of $\mathrm{TH}$ receptor isoforms are taking place, under TH control (Kaplan \& Yaskoski 1981, Silva \& Larsen 1982, Bradley et al. 1992, Santini et al. 1999), which interferes with the pattern of $\mathrm{GH}$ gene response to $\mathrm{T} 3$ observed in adult rats, in which the adult isoforms predominate. Furthermore, in the NP, the $\alpha-2$ isoform of TR (TR $\alpha 2$ ) is highly expressed, which prevents, in a certain degree, the binding of other $\operatorname{TR}$ isoforms $(\operatorname{TR} \alpha 1, \beta 1$, and $\beta 2)$ to the DNA-binding domain (DBD) of the T3 target genes (Bradley et al. 1992), and taking into account that T3-binding domain is missing in the TR $\alpha 2$, this might prevent, in some way, the impact of TH on the expression of many genes in this period of development, in which the patterns of gene expression that will persist in adult life is being settled (Csaba \& Nagy 1985). 
We assume that the somatotrophs, in particular, could be targeted by this kind of regulation during the period in which the animals were being exposed to high $\mathrm{T} 3$ doses, which might explain why the expression of GH gene remained unchanged when the neonatal rats were treated with $\mathrm{T} 3$ for longer periods (15 and 30 days). Considering the critical role of $\mathrm{GH}$ for growth and development, these adjustments might guarantee an adequate maturation and differentiation of several tissues that occur predominantly during the first month of life (Van der Linden et al. 1992, Cernohorsky et al. 1998).

The differential response of GH mRNA expression to 5-, 15-, and 30-day period of T3 treatment could be a result of any of the events described above and the causes that elicit these alterations deserve to be further addressed in models, in which somatotrophs could be specifically evaluated. These findings show the complexity of GH gene control by TH and its dependence on the animal age and treatment length. These adjustments might be important later, in adulthood, considering the influence of $\mathrm{GH}$ to determine the body lean and fat mass. On the other hand, the induction of hyperthyroidism from P1 to P30 reduced the GH gene expression in adulthood, which was accompanied by physiological repercussions compatible with GH deficiency (Table 2 and Fig. 3).

These findings are consistent with those of Walker \& Courtin (1985). These authors demonstrated a decrease of GH content in pituitary of adult rats after induction of HyperPNT. However, they observed a significant decrease in T3, T4, and TSH serum concentrations and suggested that the HyperPNT causes a permanent dysfunction of the HPT axis in adult rats. Bakke et al. (1974) also proposed that hyperthyroidism triggered during the NP leads to hypothyroidism in adult rats.

In our study, we cannot ascribe that the decrease of $\mathrm{GH}$ mRNA content in adult rats subjected to HyperPNT was due to a permanent dysfunction of the HPT axis, since T3 and T4 levels remained similar to the values of the control group. Furthermore, some genes that are upregulated by $\mathrm{TH}$, like the myoglobin gene (Dos Santos et al. 2001, Giannocco et al. 2004), actually present an increased expression in this experimental model (data not shown). Thus, it is possible that the discrepancies between the results presented could be explained by differences in the treatment scheme, i.e., length of treatment and $\mathrm{T} 4$ administration.

Thereby, lower GH gene expression in the 90-day-old rats could be a consequence of different patterns of expression of $\mathrm{TH}$ receptors or of deiodinases in a tissue-specific response that has been established by the exposure of transient hyperthyroidism soon after birth, as already discussed. We assume that the exposure of animals to high doses of T3 in the first weeks of life has triggered adjustments in the set point of several genes, like GH gene, resulting in a long-term variation in its responsiveness to T3. These animals possibly developed a pattern of GH gene expression programmed to respond to high T3 levels, as they were in the physiological range; as a consequence, when the T3 treatment was disrupted and T3 serum concentration returned to its physiological level, somatotrophs responded as if the animals were in a hypothyroid state. It should be stressed that this kind of response seems to be specific for somatotrophs, otherwise we would detect variations in $\mathrm{T} 3$ and $\mathrm{T} 4$ serum concentrations, which was not the case.

Physiological repercussions indicative of GH deficiency, as diminished BW and length, were also detected in adult rats exposed to hyperthyroidism during the NP, which led us to presume that reduced GH mRNA content effectively led to a lower GH secretion. The decrease in lean body mass (LBM) and BMD is also an indication that GH secretion is impaired, considering the essential role of $\mathrm{GH}$ to determine these parameters in vertebrates (Leal Cerro 2004).

The LBM is represented mainly by the skeletal muscles, which are important target of insulin action. In addition, the skeletal muscles are the tissues that continuously exert mechanical forces on bones. Thus, if on one hand, the decreased LBM could influence the glucose homeostasis, then on the other hand, it could attenuate the mechanical forces to the bones, preventing fractures that could take place, since BMD was decreased in animals subjected to transient hyperthyroidism.

Taking together, these results indicate that $\mathrm{TH}$ has established a new program for the expression of GH gene and that this molecular modification led to physiological alterations, in the adult life, which could be an adaptation to the new steady-state condition reached.

In conclusion, the present study demonstrates that $\mathrm{GH}$ gene expression is regulated by T3 in an age-dependent manner and provides a molecular basis to explain the physiological repercussions observed in growth and metabolism in adult rats that were transiently exposed to hyperthyroidism during precocious postnatal life.

\section{Acknowledgements}

The authors are grateful to Dr Rosângela Aparecida dos Santos Eichler and Prof. Rui Curi for their critical comments on the manuscript.

\section{Funding}

This work was supported by grants from Fundação de Amparo à Pesquisa do Estado de São Paulo (FAPESP 00/08755-0) and Conselho Nacional de Desenvolvimento Científico e Tecnológico (CNPq - 305427/2003-2). The authors declare that there is no conflict of interest that would prejudice the impartiality of this scientific work. 


\section{References}

Bakke JL, Lawrence N \& Wilber JF 1974 The late effects of neonatal hyperthyroidism upon the hypothalamic-pituitary-thyroid axis in the rat. Endocrinology 95 406-411.

Bates JM, St Germain DL \& Galton VA 1999 Expression profiles of the three iodothyronine deiodinases, D1, D2, and D3, in the developing rat. Endocrinology 140 844-851.

Bradley DJ, Towle HC \& Young WS 1992 Spatial and temporal expression of alpha- and beta-thyroid hormone receptor mRNAs, including the beta 2-subtype, in the developing mammalian nervous system. Neuroscience 12 2288-2302.

Cernohorsky J, Kolar F, Pelouch V, Korecky B \& Vetter R 1998 Thyroid control of sarcolemmal $\mathrm{Na}+/ \mathrm{Ca} 2+$ exchanger and SR Ca2 + -ATPase in developing rat heart. American Journal of Physiology 275 H264-H273.

Chomczynski P \& Sacchi N 1987 Single-step method of RNA isolation by acid guanidinium thiocyanate-phenol-chloroform extraction. Analytical Biochemistry 162 156-159.

Csaba G \& Nagy SU 1985 Influence of the neonatal suppression of tsh production (neonatal hyperthyroidism) on response to tsh in adulthood. Journal of Endocrinological Investigation 8 557-559.

Dillmann WH, Berry S \& Alexander NM 1983 A physiological dose of triiodothyronine normalizes cardiac myosin adenosine triphosphatase activity and changes myosin isoenzyme distribution in semistarved rats. Endocrinology 112 2081-2087.

Dos Santos RA, Giannocco G \& Nunes MT 2001 Thyroid hormone stimulates myoglobin expression in soleus and extensorum digitalis longus muscles of rats: concomitant alterations in the activities of Krebs cycle oxidative enzymes. Thyroid 11 545-550.

Dussault JH \& Labrie F 1975 Development of the hypothalamic-pituitarythyroid axis in the neonatal rat. Endocrinology 97 1321-1324.

Fisher DA \& Lakshmanan J 1990 Metabolism and effects of epidermal growth factor and related growth factors in mammals. Endocrine Reviews $\mathbf{1 1}$ 418-442.

Giannocco G, Dossantos RA \& Nunes MT 2004 Thyroid hormone stimulates myoglobin gene expression in rat cardiac muscle. Molecular and Cellular Endocrinology 226 19-26.

Harvey CB \& Williams GR 2002 Mechanism of thyroid hormone action. Thyroid 12 441-446.

Heron MI \& Rakusan K 1996 Short- and long-term effects of neonatal hypoand hyperthyroidism on coronary arterioles in rat. American Journal of Physiology 271 H1746-H1754.

Kaplan MM \& Yaskoski KA 1981 Maturational patterns of iodothyronine phenolic and tyrosyl ring deiodinase activities in rat cerebrum, cerebellum, and hypothalamus. Journal of Clinical Investigation 67 1208-1214.

Kominami R, Yasutaka S, Taniguchi Y \& Shinohara H 2003 Proliferating cells in the rat anterior pituitary during the postnatal period: immunoelectron microscopic observations using monoclonal anti-bromodeoxyuridine antibody. Histochemistry and Cell Biology 120 223-233.

Leal Cerro A 2004 Long-term challenges in growth hormone treatment. Hormone Research 62 23-30.

Maniatis T, Fritsch EF \& Sambrook J 1989 Extraction, purification and analysis of mRNA from eucariotic cells In Molecular Cloning: a Laboratory Manual, edn 2, pp 188-209. New York: Cold Spring Harbor Laboratory Press.

Marta CB, Adamo AM, Soto EF \& Pasquini JM 1998 Sustained neonatal hyperthyroidism in the rat affects myelination in the central nervous system. Journal of Neuroscience Research 15 251-259.

Mauras N, O'Brien KO, Welch S, Rini A, Helgeson K, Vieira NE \& Yergey AL 2000 Insulin-like growth factor I and growth hormone $(\mathrm{GH})$ treatment in GH-deficient humans: differential effects on protein, glucose, lipid, and calcium metabolism. Journal of Clinical Endocrinology and Metabolism 85 1686-1694.

Nakahara J, Seiwa C, Tan-Takeuchi K, Gotoh M, Kishihara K, Ogawa M, Asou H \& Aiso S 2005 Involvement of CD45 in central nervous system myelination. Neuroscience Letters 379 116-121.
Novotny J, Bourova L, Malkova O, Svoboda P \& Kolar F 1999 G proteins, beta-adrenoreceptors and beta-adrenergic responsiveness in immature and adult rat ventricular myocardium: influence of neonatal hypo- and hyperthyroidism. Journal of Molecular and Cellular Cardiology 31 761-772.

Okada S \& Kopchick JJ 2001 Biological effects of growth hormone and its antagonist. Trends in Molecular Medicine 7 126-132.

Pasquini JM \& Adamo AM 1994 Thyroid hormones and the central nervous system. Developmental Neuroscience 16 1-8.

Pracyk JB, Seidler FJ, McCook EC \& Slotkin TA 1992 Pituitary-thyroid axis reactivity to hyper- and hypothyroidism in the perinatal period: ontogeny of regulation of regulation and long-term programming of responses. Journal of Developmental Physiology 18 105-109.

Robson H, Siebler T, Shalet SM \& Williams GR 2002 Interactions between GH, IGF-I, glucocorticoids, and thyroid hormones during skeletal growth. Pediatric Research 52 137-147.

Samuels HH \& Shapiro LE 1976 Thyroid hormone stimulates de novo growth hormone synthesis in cultured GH1 cells: evidence for the accumulation of a rate limiting RNA species in the induction process. PNAS 73 3369-3373.

Santini F, Chiovato L, Ghirri P, Lapi P, Mammoli C, Montanelli L, Scartabelli G, Ceccarini G, Coccoli L, Chopra IJ, Boldrini A \& Pinchera A 1999 Serum iodothyronines in the human fetus and the newborn: evidence for an important role of placenta in fetal thyroid hormone homeostasis. Journal of Clinical Endocrinology and Metabolism 84 493-498.

Schneider MJ, Fiering SN, Pallud SE, Parlow AF, St Germain DL \& Galton VA 2001 Targeted disruption of the type 2 selenodeiodinase gene (DIO2) results in a phenotype of pituitary resistance to T4. Molecular Endocrinology 15 2137-2148.

Silva JE \& Larsen PR 1982 Comparison of iodothyronine 5'-deiodinase and other thyroid-hormone-dependent enzyme activities in the cerebral cortex of hypothyroid neonatal rat, Evidence for adaptation to hypothyroidism. Journal of Clinical Investigation 70 1110-1123.

St Germain DL \& Galton VA 1997 The deiodinase family of selenoproteins. Thyroid 7 655-668.

Stikkelbroeck NM, Oyen WJ, van der Wilt GJ, Hermus AR \& Otten BJ 2003 Normal bone mineral density and lean body mass, but increased fat mass, in young adult patients with congenital adrenal hyperplasia. Journal of Clinical Endocrinology and Metabolism 88 1036-1042.

Teerds KJ, de Rooij DG, de Jong FH \& van Haaster LH 1998 Development of the adult-type Leydig cell population in the rat is affected by neonatal thyroid hormone levels. Biology of Reproduction 59 344-350.

Tu HM, Legradi G, Bartha T, Salvatore D, Lechan RM \& Larsen PR 1999 Regional expression of the type 3 iodothyronine deiodinase messenger ribonucleic acid in the rat central nervous system and its regulation by thyroid hormone. Endocrinology 140 784-790.

Van der Linden GC, Simonides WS \& van Hardeveld C 1992 Thyroid hormone regulates $\mathrm{Ca}(2+)$-ATPase mRNA levels of sarcoplasmic reticulum during neonatal development of fast skeletal muscle. Molecular and Cellular Endocrinology 90 125-131.

Volpato CB \& Nunes MT 1994 Role of thyroid hormone in the control of growth hormone gene expression. Brazilian Journal of Medical and Biological Research 27 1269-1272.

Volpato CB \& Nunes MT 2001 Functional evidence for the presence of type II 5'-deiodinase in somatotropes and its adaptive role in hypothyroidism. Neuroendocrinology 74 220-226.

Walker P \& Courtin F 1985 Transient neonatal hyperthyroidism results in hypothyroidism in the adult rat. Endocrinology 116 2246-2250.

Webb P 2004 Selective activators of thyroid hormone receptors. Expert Opinion on Investigational Drugs 13 489-500.

White P, Burton KA, Fowden AL \& Dauncey MJ 2001 Developmental expression analysis of thyroid hormone receptor isoforms reveals new insights into their essential functions in cardiac and skeletal muscles. Federation of American Societies for Experimental Biology Journal 15 1367-1376.

Williams GR, Harney JW, Forman BM, Samuels HH \& Brent GA 1991 Oligomeric binding of T3 receptor is required for maximal T3 response. Journal of Biological Chemistry 266 19636-19644. 
Wolf G 2002 The regulation of the thyroid-stimulating hormone of the anterior pituitary gland by thyroid hormone and by 9-cis-retinoic acid. Nutrition Reviews 60 374-377.

Yamazoe Y, Murayama N, Shimada M \& Kato R 1989 Thyroid hormone suppression of hepatic levels of phenobarbital-inducible p-450b and p-450e and other neonatal p-450s in hypophysectomized rats. Biochemical and Biophysical Research Communications 160 609-614.

Yilmazer-Hanke DM, Hantsch M, Hanke J, Schulz C, Faber-Zuschratter $\mathrm{H} \&$ Schwegler H 2004 Neonatal thyroxine treatment: changes in the number of corticotropin-releasing-factor (CRF) and neuropeptide y (NPY) containing neurons and density of tyrosine hydroxylase positive fibers (th) in the amygdala correlate with anxiety-related behavior of wistar rats. Neuroscience 124 283-297.

Received in final form 2 April 2006

Accepted 25 April 2006

Made available online as an Accepted Preprint 10 May 2006 